\title{
Profiles of Ferry Services in and Around Howrah Ghats
}

\author{
Debarchana Biswas \\ Senior Research Fellow, Department of Geography, University of Calcutta \\ E-Mail: debarchana.biswas@gmail.com
}

\begin{abstract}
On the off chance that one thinks about the most ideal approach to drag oneself alongside the madding crowd easily and exertion, at that point no preferred choice over ferry services would ring a bell. A ferry conveys passengers, vehicles and cargos as a piece of the general population transport framework by permitting direct travel between various places at a capital cost much lower than bridges or tunnels. This paper expects to make an examination and appraisal of the commuters' observation on ferry benefits on picking this mode, on time specifics, to discover commuters' discernment on administration of Ghats and to uncover the suburbanites' concern the individuals who are profiting from ferry services. The study area centers on the Howrah Unit under Hooghly Nadi Jalapath Paribahan Samabay Samity Ltd. (HNJPSS) which incorporates Howrah (I and II), Armenian, Fairlie, Babughat, Shovabazar, Ahiritola and Bagbazar Ghats. In West Bengal, especially there is an enormous possibility for improvement of inland water transport system along the river Hooghly which is navigable throughout the year and can possibly assume an essential part in the regional economy both urban and rural. Unfortunately in West Bengal, this method of transport has been liable to nonstop carelessness. The study has been conducted on random sample survey and secondary information has been obtained from HNJPSS. This study reveals that the glory of ferry services in Kolkata is losing day by day. Beautification of each Ghat is necessary alongside appropriate network inside a region. So in general up gradation of Ghats and ferry system are alluring as it will encourage economic development in Kolkata and its environment.
\end{abstract}

Keywords: Exertion, suburbanites, appraisal, beatifications, Alluring

\section{INTRODUCTION}

The transport industry possesses a significant place in the economic improvement of any nation. The four wings of transport i.e. railway, road, air and water have their four particular part to play. In India, major cities grew up in colonial interest without having any reasonable premonition and anticipating future advancement. In West Bengal, especially there is a tremendous possibility for advancement of inland water transport along the river Hooghly which is navigable throughout the year and in addition has enough possibilities to assume an important part in the regional economy- both urban and rural.

The port oriented gateway city of Kolkata and its hinterland of the whole eastern India amid the British time period was amazingly outstanding for its inland route framework which alongside the road transport framework, acted as feeders of the railroads (Dey T., 2013).
The accounts of Alfred Brame mentioned that "In the days before steamers and railways made their appearance in India, the principal means of transport in Bengal and the province of Hindustan was by boats, laboriously towed or sailed over the magnificent waterways of the Ganges and its affluent" (Munshi, 1980).

From HNJPSS it has been pointed out that in West Bengal, this method of transport has been liable to constant carelessness. In the year 1995-96, ferry services reached its peak with 26.8 lakhs passengers per month. The year 200607 witnessed a decrease of passengers to17 lakhs/month. This rate of huge decrease in the passengers' flow was predominantly because of the absence of maintenance and low speed of the vessels. It is extremely discouraging that the water transport especially the benefits of ferry services are extraordinarily under-used however having extraordinary probability.

Shockingly, this ferry services secures a large portion of the monetary and ecological points of interest. It is one of the least expensive movement implies with high stacking limit and low support cost which does not require any exceptional framework like streets, railroads and airplane terminals. (Dey T. , 2013)

As indicated by Transport Planning and Traffic Engineering Directorate Department, (Government of West Bengal,1976) the vast majority of the operators were found to utilize just wooden body launches and HNJPSS and WBSTC were found to use few steel body vessels for which these wooden bodies are inclined to mischances. In addition, the gangways and pontoon jetties don't have any protected passage making it clumsy. Absence of terminals, repairing centers, river traffic management system, and lack of lighting and facilities of toilets influence the ferry to benefit substantially less alluring to the Kolkatans. In spite of having around $14,500 \mathrm{~km}$ of navigable waterways, it plays only a marginal part in India $(0.15 \%)$ in inland navigation in comparison to Germany (20\%) and Bangladesh (32\%) (Abler, Adams, \& Gould, 1971)

For every one of these reasons, ferry services lost its own glory. But in order to mitigate congestion, emphasis must be put on water transport for the betterment of the service. In Kolkata, $65 \%$ of the streets have poor level of administration. $100 \%$ of the major streets have movement network bolt and for which clog happens. In addition, the quantity of pedestrians has increased and sidewalks have been choked by car parking. Another important issue is the 
expansion in the populace which additionally creates numerous pressures on the road networks. So as to facilitate these kinds of pressures on roadways, it is essential to take care of the ferry services in Kolkata as an elective method of transport separated from metro services. Ferries can accomplish something other than moving commuters. Ferry services can ease swarming and fill in as a crisis transportation benefit amid the season of emergency.

The administration ought to enhance the ferry services keeping in mind the end goal to improve wellbeing and security for future age. In addition, to enhance air quality and also to enhance quality of life this ultimately leads to sustainable growth of eco-friendly environment. But the gradual decline of navigability of the river, along with the development of other means of public and private transport services led to inefficiency and weakening of ferry services on river Hooghly (Munshi, 1980).

\section{OBJECTIVE}

The major objective of this study is to make an analysis and assessment of the people's perception on ferry service which requires simultaneous monitoring and management for proper functioning. The paper also argues regarding the passenger's perception on management of Ghats and to find out commuter's perception on the betterment of the Ghats so as to improve the overall services.

\section{METHODOLOGY}

The present examination depends on the empirical observation and primary data and information gathered through field review with the assistance of very much outlined questionnaire and direct responses of the respondents. Secondary information has been collected from HNJPSS. Simple random sampling methods are applied to collect primary data. The collected data has been tabulated with suitable statistical and mathematical calculations. The data is used to prepare spatial representations by different cartographic techniques. At last a few issues are set apart with a few recommendations for the advancement of the ferry services.

\section{STUDY AREA}

Howrah Unit under HNJPSS is selected as the study area (Fig 1) which includes HOWRAH GHAT (I \& II), ARMENIAN GHAT, FAIRLIE GHAT, CHANDPAL or the BABUGHAT, SHOVABAZAR, AHIRITOLA and BAGBAZAR GHATS. All these Ghats are under aegis of HNJPSS. As Howrah Unit has been detected for study so it is very important to discuss the area and extent of the Ghats.

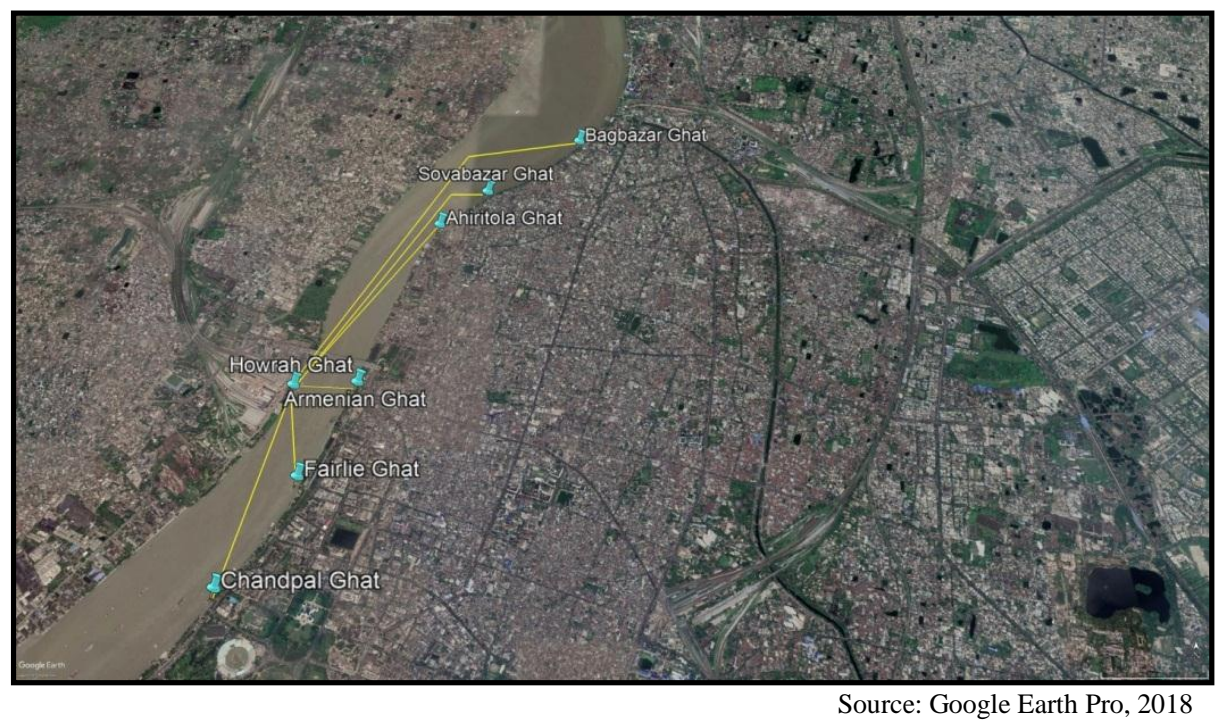

Fig. 1 Location of Ferry Ghats on both sides of Hugli River

Howrah Ghat lies on the west bank of River Hooghly covering an area of about 750 sq.km $\left(22^{\circ} 34^{\prime} 56^{\prime \prime} \mathrm{N}, 88^{\circ}\right.$ 20’37' E).

Babughat covering an area of around 520 sq. km with coordinates $22^{\circ} 33^{\prime} 58^{\prime \prime} \mathrm{N}, 88^{\circ} 20^{\prime} 22^{\prime}$ " E. the distance between Haora and Babughat is around 1.35 kilometers.

Armenian Ghat on the east bank of River Hooghly lies at $22^{\circ} 34^{\prime} 49^{\prime \prime} \mathrm{N}$ and $88^{\circ} 20^{\prime} 50^{\prime \prime} \mathrm{E}$ and is 0.45 kilometers away from the Howrah Ghats.
Fairlie Ghat also lies on the east bank of River Hooghly at $22^{\circ} 34^{\prime} 49^{\prime \prime} \mathrm{N}, 88^{\circ} 20^{\prime} 51^{\prime \prime}$ E located at a distance of 0.81 kilometers from Howrah.

Under the Howrah Unit, Babughat is the farthest, lying at a distance of about 7.40 kilometers on $22^{\circ} 30^{\prime} 49^{\prime \prime} \mathrm{N}$ and 88 19'39’'E co-ordinates.

\section{HISTORY OF THE FERRY SERVICES UNDER HNJPSS}

The transport industry involves a critical place in the financial improvement of any nation. The four wings of 
transport i.e. railways, roadways, airways and waterways have their particular part to play. In India and in other SAARC nations as well, major cities grew up in colonial interest without having any clear foresight and planning for future development.

The long stretch of river Hooghly on the western side of Kolkata is characterized by presence of numerous Ghats, which have sprung up during different periods of history. They have served important purposes of embankment protection apart from the services they rendered for trading, loading of merchandise on barges including vessels carrying passengers and for other religious and household chores (Dey B. , 1995). The first regular steamer service was started in 1834 on Ganga, under the direct control of the East India Company (Munshi, 1980).

In West Bengal especially there is enormous possibility for advancement of inland water transport along the river Hooghly which is traversable consistently. It has enough conceivable outcomes to assume an indispensable part in the regional economy - urban and rural. To express the historical backdrop of Hooghly Nadi Jalapath Paribahan Samabay Samity Ltd., it is important to review the story of two urban communities Kolkata and Howrah which are separated by the waterway Ganges but linked with bridges. It was a non-profit making organization for inland water transport in Kolkata (Government of West Bengal, 1990).

Kolkata is a critical focal point of attraction from all perspectives - socially, commercially, socially, financially and while Howrah is a mechanical town - a home of designing ventures, the Sheffield of Bengal. So both the urban areas are indivisibly connected up with each other. The two urban communities have in reality turned into a hive of chaotic exercises inside two or three decades. So there has been an extraordinary ascent in the rate of populace, vehicles, movement inside the urban areas and rural areas. Also, Howrah railway station being the principle door to Kolkata from many states of the country, a surging flow of population trek towards the cities for their employment as well as other necessities. The only passage to Kolkata is the Rabindra setu which needs to eject every day a large number of individuals and unending fleet of cars. Subsequently the bridge turns out to be essentially congested and broken down and enormous bottle necks are made on the extension.

Against this foundation, the Left Front Government of West Bengal took up a program of operating launch services on the river Ganges to give alleviation to ruthless congestion on Howrah Bridge and decided to entrust the responsibility of controlling the services on a transport co-operative society As needs be HNJPSS begun a trail services on 2nd May, 1980 with just 2 launches. Be that as it may, inside so short a period of 7 to 8 years, the administration has swelled to sizeable extent much to the help of travelling public. Over 30 launches are now in fact plying at present and nearly a lakh of passengers are travelling daily through these launches within 13 ferry stations. With due care and duties, HNJPSS spread out the system of network by dispatching ferry services from 2-18 stations covering 35 kilometers of the river inside a couple of years. With their limited resources a couple of workable terminals were additionally made for introduction of launch services in rural areas. Their whole transport is currently obliging the need of 1 lakh suburbanites daily and has normally turned into a necessary piece of regional transport. The more the services spread out, the more was the chance of employment. At present the strength of enlisted staff is more than 350. HNJPSS are also earning from allied industries and traders. So with a clear view of the ebb and flow of passengers the next part of HNJPSS 's scheme is to open more ferry stations and to build up more new motor vessels. In any case, despite the fact that their prosperity is far underneath the pinnacle yet has been incredibly refreshing by people in general. So accurately all these are HNJPSS's advantages and maybe alleviation and comfort...

\section{DISCUSSION AND ANALYSIS}

Out of 100 respondents, $62 \%$ are male and $38 \%$ are female. Most of them commute from North Kolkata and almost all of them belong to the age group of 30-44 years. It has been found that most of them are employed in non-governmental sectors with monthly income of Rs.5000-10000.

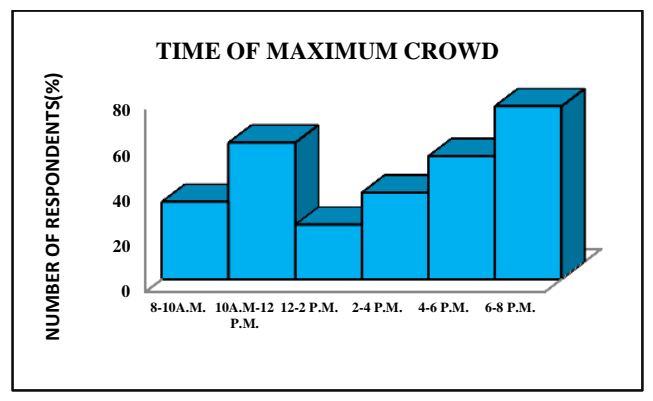

Fig. 2 Time of Maximum Crowd

Now coming to the commuter's preference on opting the ferry services most of them availed for their personal and service purposes and maximum of them think that the journey is of immense pleasure with easy access to destination along with cheap fare. Most of them are satisfied with the frequency of ferry services. Maximum passengers commute during morning and afternoon on a daily basis mainly those who are engaged in non-governmental sectors and school- college goers. (Fig 2) As a result of which maximum crowd is noticed during 10 a.m-12 p.m. followed by 6 p.m. -8 p.m.

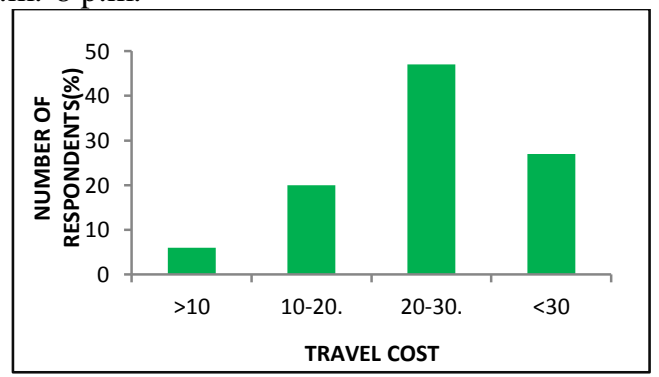

Fig. 3 Travel Cost opted in other modes of transport 
Most of the surveyed populations i.e. about $66 \%$ have the facilities of alternative modes of transport and maximum of them have chosen bus as an alternative mode. So interestingly people who avail ferry services as their daily mode of transport spend a maximum of Rs. 10-15/ day whereas others have to spend Rs.20-30/day while availing alternate mode of transport (Fig 3).So it is very economical mode of transport. But in spite of low cost, people still prefer to opt for alternative modes of transport because the speed of vessels are very slow as well as it is not well connected with whole Kolkata. Connectivity plays a very important role in any transport network because it determines how much a place is connected by other places. (Kansky, 1963). 84\% of the commuters' value ferry services as they want to maintain the glory in Kolkata. Most of the commuters urge that the ferry services should be connected with whole Kolkata as it offers very convenient and comfortable journey.

While analyzing the passengers perception on safe journey, they recommend it as a safe one but still $13 \%$ of them consider ferry journey not so much safe as they feel unsecure may be due to lack of lightening. Majority of the commuters buy single trip tickets and rest prefer to buy coupons. Around $2 / 5^{\text {th }}$ strongly feel that metro type ticketing system should be introduced. In case of fare structure, majority feel that the fare is sufficient enough for the maintenance of vessels and Ghats. $3 / 5^{\text {th }}$ of the majority feel that the Ghats need to be managed properly as they feel that the condition of the Ghats is declining day by day.

They imagine that the principle purposes behind the decay have been the deficient upkeep and reckless conduct of suburbanites. Carelessness with respect to concerned specialist has additionally been distinguished as an essential reason behind its decline (Fig 4).

Majority of the commuters have their opinion that they suffers from low speed service. Around $70 \%$ blame on lack of maintenance and fund followed by poor lightening and cleanliness in and around the Ghats. They imagine that it is the aggregate duty of government to keep up and deal with the Ghats. $98 \%$ trust that if the duty of appropriate administration is embraced by particular expert, ship administrations will enhance complex and will give adequate degree to more agreeable and helpful method of transport.

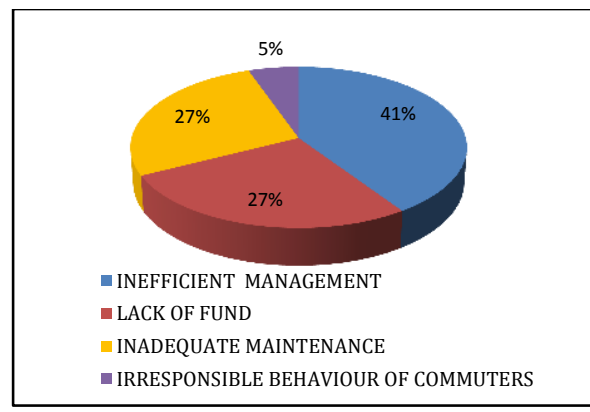

Fig. 4 Reasons for decline of ferry service

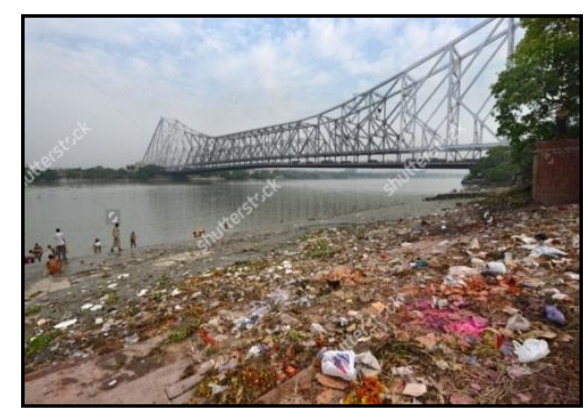

Fig. 5 Degrading water quality

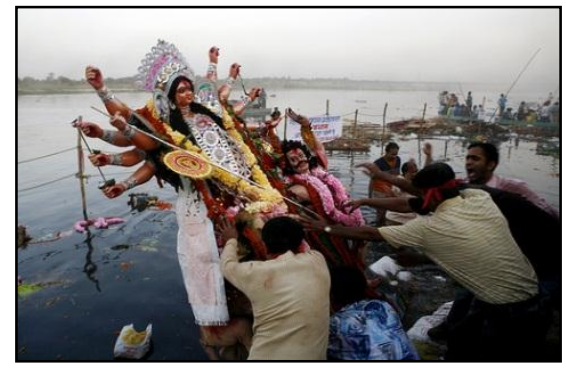

Fig. 6 Reasons for degradation of water quality

Most of the peoples' perception that the Ghats are debasing the water quality gradually and the conceivable reasons are littering by the commuters and even by the authorities. Government should mindful of these issues and genuine arrangements should be actualized to spare nature in close future(Fig 5,6,7).



Fig. 7 Reasons for debasing water quality

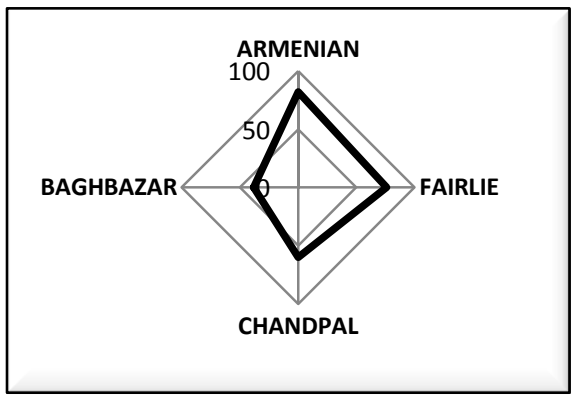

Fig. 8 Daily Number of Trips from Howrah Ghat

Hooghly Nadi Jalapath Paribahan Samabay Samiti Ltd. oversees ferry services framework in Kolkata as it utilize through one of the world's busiest safe conduits. From District Statistical Handbook, Kolkata, (1995-2010) it has been pointed out that HNJPSS operates 20 routes with an average trips operated between Howrah and Armenian are 82 per day (Fig 8) which is highest due to large concentration of people in and around the area. 
Based on it its present status, the recurrence of ferry services are greatest amid crest hours that is between 9 a.m. - 12 p.m. and 4 p.m. - 8 p.m. (Fig 9).The time interval during peak hours reduced to $10 \mathrm{mins}$ to serve the people better. Vessels are also increased to 5 during peak hours to manage the huge rush.
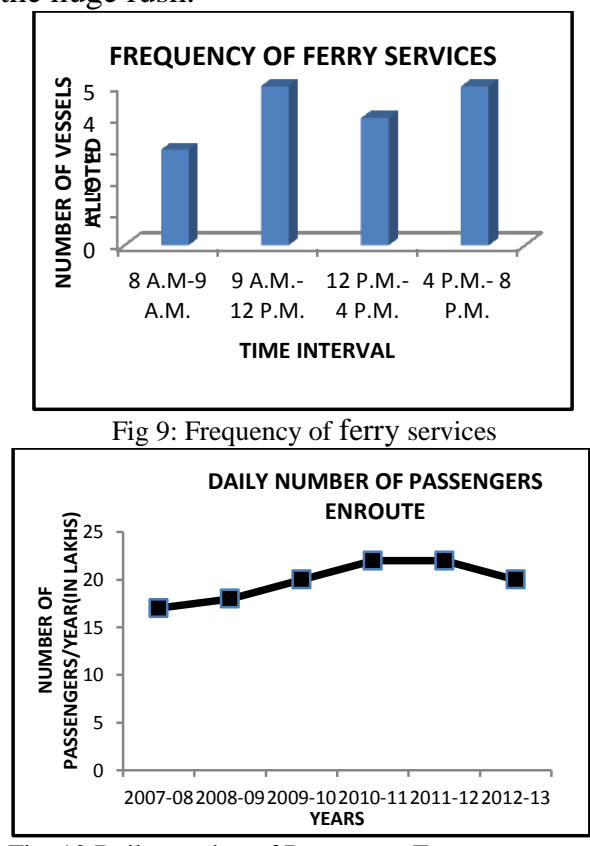

Fig. 10 Daily number of Passengers Enroute

Hence in the times of its initiation, it upheld a tremendous populace. The day by day passengers' volume has been expanding step by step over the years. In 2007-08 the volume of passengers every year was around 17 lakhs and it has expanded to 22 lakhs (approx.) in 2012-13 (Fig 10). Yet, because of absence of fund and legitimate support, staff qualities are diminishing step by step in this agreeable segment for which the official works of HNJPSS is also hampered. (Fig 11). The financial position of HNJPSS has been weakening for a genuinely prolonged stretch of time. Despite the fact that financial position of this cooperative sector expanded from Rs. 947.30 lakhs in 2010-11 to Rs.1012.74 lakhs in 2015-16. (Fig 12) Still benefit of Rs.12.28 lakhs was last made in 2010-11. From that point forward it has encountered misfortunes at any rate for about Rs.12.41 lakhs in 2011-12. Yet at the same time HNJPSS needs to confront an enormous loss of Rs.36.25 lakhs in 2015-16 because of beginning of increment in business cost, fuel and lubricant costs, repairs and maintenance cost , establishment cost and so forth. From that point forward it has encountered a constant rate of losses at a gentle rate.

Moreover absence of appropriate incorporation amongst public and private sectors generate infrastructural problems to ferry services. Absence of proper terminals, ticketing system are some of the basic problems that ferry services of Kolkata are currently facing. Water pollution, siltation on river Hooghly and sometimes bank erosion are additional issues which persistently bring down the level of this system.

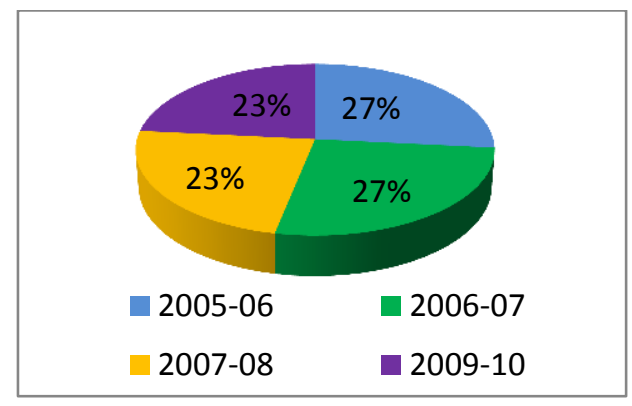

Fig. 11 Staff strength of HNJPSS

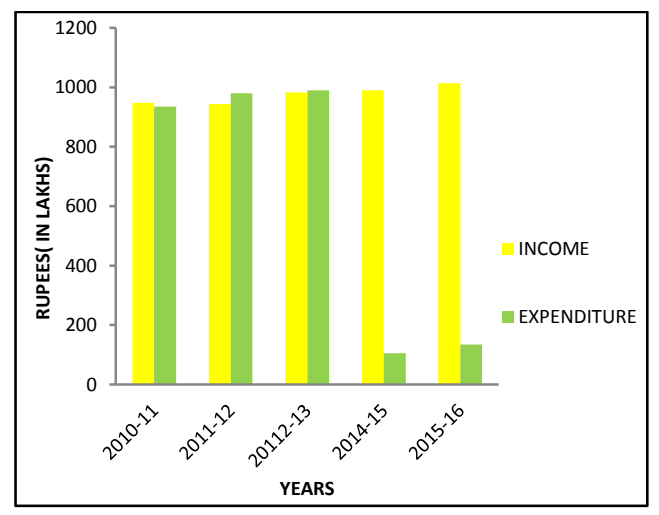

Fig.12 Income \& Expenditure of HNJPSS (2010-13)

So the general significance of ferry service is under HNJPSS is boundless. Ferry services of Kolkata have that potentiality to ease of the land pressure and to give quick and blockage free transport network with proper mass transport facility. Despite the fact that ferry service over the river is more gainful because of short distance, low cost and immense demand, there are plentiful conceivable outcomes to utilize this waterway to link the south western part of Kolkata with focal and northern part through quick moving launches, with the goal that pressure can be reduced on land surface. It is an economic and gainful mode for movement and for beguilement purposes.

\section{CONCLUSION}

If one thinks of the best way of crawling past the madding crowd with ease and afford, then no better options than ferry services would come to one's mind. Analyzing all the aspects of availing ferry services, the commuters would find it very hard to locate the negative aspects of it. Though their popularity have drastically come down in the era of luxurious cabs and bikes, still then the ferry services in Kolkata has figured out how to confront the chances and flourish as an essential transport network with its same old promise of protected and accommodating way of life. However, Kolkata has tremendous but to a great extent undiscovered potential to utilize its inland river system Hooghly for passenger movement purpose to dispose of over blockage on road network. (Government of West Bengal,1976).The present situation demonstrates that the greatness of ferry services in Kolkata is losing its significance step by step. It is expected that if sufficient 
measures are not taken to enhance the current condition, Kolkata should compromise with this extremely old transport framework.

A clear policy for ferry services is needed which will allow this mode to survive. Proper management of each and every Ghats is very necessary. Proper and regular dredging of the river is suggested with proper lightening of each and every Ghats. Beautifications of each and every Ghats are compulsory by banning the waste disposal into the river and that is extremely important to pull in millions from all over Kolkata. Each and every Ghats should be well connected with buses; auto, train and other para transit services like auto rickshaws, cycle rickshaws so that connectivity within a region also increases.

Modern vessels like water taxi, more motor launches should be introduced in large numbers to cope up during rush hours. Route length should be increases to ease the pressure of roads and railways. There is a huge potential for longer version of launch service that is available now. So in overall up gradation of Ghats and ferry services are desirable as it will rather facilitate economic growth in Kolkata and in surrounding areas. The need of hour is not so much discourse but rather more activity. Rather than sitting idle on more investigations, it can be put to better utilize modernizing the river transport. It is just the method of transport in worldwide parameter which will have a superior prospect.

\section{REFERENCES}

[1] Abler, R., Adams, J. S., \& Gould, P. (1971). The spatial organization: geographer's view of the world. New Jersey: Prentice-Hall Inc.

[2] Dey, B. (1995). The history of Kolkata port and the Hooghly river and its future. In S. C. Chakraborty (Ed.), Port of Calcutta, 125 Years (1870 - 1995). Kolkata: Calcutta Port Trust, Kolkata.

[3] Dey, T. (2013). Viability of passenger transport system through Hooghly River in Kolkata city. Hill Geographer, XXIX (2), 1-16.

[4] Government of West Bengal. (1990). Statistical data on the Calcutta metropolitan district. Kolkata: Calcutta Metropolitan Development Authority, Kolkata.

[5] Government of West Bengal. (1995-2008). District statistical handbook. Kolkata. Kolkata: Bureau of Applied Economics and Statistics, Kolkata.

[6] Government of West Bengal. (1976). Traffic operation and management improvement programme (Approach paper), Report No. 34. Kolkata: Traffic and Transportation Planning Circle Directorate of Planning, CMDA, Traffic Department Calcutta Police, Kolkata.

[7] Kansky, K. J., (1963). Structure of transportation network: relationships between network geometry and regional characteristics (Vol. Issue 84). Chicago: University of Chicago.

[8] Munshi, S. K., (1980). Geography of transportation in eastern India under the British raj. Kolkata: Centre for Studies in Social Sciences, Calcutta by K.P. Bagchi. 